\title{
Os conselhos de saúde como estratégias da participação popular no SUS: uma revisão integrativa
}

\author{
Health councils as strategies for popular participation in UHS: an integrative review \\ Los consejos de salud como estrategias para la participación popular en el SUS: una revisión \\ integrativa
}

Recebido: 01/12/2021 | Revisado: 06/12/2021 | Aceito: 11/12/2021 | Publicado: 20/12/2021

Cíntia Maria Tagliatti Roque

ORCID: https://orcid.org/0000-0003-1428-561X

Faculdade de Ciências Médicas da Paraíba, Brasil

E-mail: cintiatagliatti15@gmail.com

Aline Cesar de Lacerda Sá

ORCID: https://orcid.org/0000-0003-4952-3198

Faculdade de Ciências Médicas da Paraíba, Brasil

E-mail: alineclacerda@gmail.com

Bartira Maraína de Souza Dantas

ORCID: https://orcid.org/0000-0001-7966-9812

Faculdade de Ciências Médicas da Paraíba, Brasil

E-mail: bartiramsd@gmail.com

Israel Dantas de Almeida

ORCID: https://orcid.org/0000-0002-6047-2240

Faculdade de Ciências Médicas da Paraíba, Brasil

E-mail: israeldantasdealmeida@gmail.com

Lucas Maroja Limeira Brito Espínola

ORCID: https://orcid.org/0000-0001-6069-6415

Centro Universitário do Estado do Pará, Brasil

E-mail: lucas21250080@aluno.cesupa.br

Maria Bianca Campos de Sousa

ORCID: https://orcid.org/0000-0002-7826-2575

Faculdade de Ciências Médicas da Paraíba, Brasil

E-mail: mabicasou@gmail.com

Natália Fernandes de Sousa Silva

ORCID: https://orcid.org/0000-0002-3400-0717

Faculdade de Ciências Médicas da Paraíba, Brasil

E-mail: natalia.astec@gmail.com

Pablo Flaviano Carolino de Aquino

ORCID: https://orcid.org/0000-0001-6542-2499 Faculdade Santa Maria, Brasil

E-mail: pabloaquino05@gmail.com

Rachel Soares Cavalcanti

ORCID: https://orcid.org/0000-0001-5317-8249

Faculdade de Ciências Médicas da Paraíba, Brasil

E-mail: rachelscanti@hotmail.com

Raimundo Fabrício Paiva Pinto

ORCID: https://orcid.org/0000-0003-4814-8031

Universalidade Federal do Ceará, Brasil E-mail: fafapaivaa@gmail.com

Tássio Rique Barboza Casé

ORCID: https://orcid.org/0000-0002-5250-3828 Faculdade de Ciências Médicas da Paraíba, Brasil

E-mail: tassiocase1@gmail.com

Luisiane de Avila Silva

ORCID: https://orcid.org/0000-0003-2991-8918

Faculdade de Ciências Médicas da Paraíba, Brasil

E-mail: luisianeavila@gmail.com

\section{Resumo}

A criação do Sistema Único de Saúde (SUS) assegurou a participação popular - sendo uma das formas os Conselhos de Saúde (CS) - nos processos de execução e fiscalização de políticas voltadas para a promoção da saúde em todo o país. Objetivou-se com esta pesquisa, avaliar como os CS atuam como estratégias de participação no desenvolvimento do SUS. Trata-se de uma revisão integrativa, com dados obtidos a partir da busca bibliográfica por meio dos descritores: 
participação popular, sistema único de saúde e conselho de saúde; foram encontrados 66 artigos. Após serem aplicados os critérios de elegibilidade e exclusão, foram selecionados 22 artigos para análise, sendo 9 indexados na base de dados BVS e 13 na SciELO. Constatou-se que os CS são ferramentas de estratégia essenciais, se apresentando como um canal direto entre a população e o desenvolvimento do SUS, contudo, mesmo que em alguns municípios a atuação deles esteja sendo desenvolvida em sua totalidade, alguns municípios não abarcam todas as atribuições que são direito da população. As dificuldades encontradas pelos conselhos envolvem uma série de causas, que vão desde o simples desinteresse pelas questões relativas dele, até questões mais complexas, como falta de comunicação entre a gestão e comunidade, infraestrutura indevida e falta de recurso financeiro. Dessa forma, estudos que discutam a participação dos CS como estratégias para participação popular no SUS são necessários para a construção de novas estratégias que possam tornar o planejamento e participação mais efetivas, atuantes e possíveis de serem realizadas em todo o país.

Palavras-chave: Participação popular; Sistema único de saúde; Conselhos de saúde.

\begin{abstract}
The creation of the Unified Health System (UHS) ensured popular participation - one of the forms being the Health Councils (HC) - in the processes of implementation and inspection of policies aimed at promoting health throughout the country. The objective of this research was to evaluate how $\mathrm{CHs}$ act as participation strategies in the development of the UHS. This is an integrative review, with data obtained from the literature search using the descriptors: popular participation, single health system and health council; 66 articles were found. After applying the eligibility and exclusion criteria, 22 articles were selected for analysis, 9 indexed in the BVS database and 13 in SciELO. It was found that $\mathrm{CH}$ are essential strategy tools, presenting themselves as a direct channel between the population and the development of the UHS, however, even if in some municipalities their work is being developed in its entirety, some municipalities do not cover all attributions that are the right of the population. The difficulties encountered by the councils involve a series of causes, ranging from simple lack of interest in their related issues, to more complex issues, such as lack of communication between management and the community, improper infrastructure and lack of financial resources. Thus, studies that discuss the participation of $\mathrm{CH}$ as strategies for popular participation in the UHS are needed to build new strategies that can make planning and participation more effective, active and possible to be carried out across the country.
\end{abstract}

Keywords: Popular participation; Unified health system; Health councils.

\title{
Resumen
}

La creación del Sistema Único de Salud (SUS) aseguró la participación popular - una de las formas son los Consejos de Salud (CS) - en los procesos de implementación y fiscalización de políticas orientadas a promover la salud en todo el país. El objetivo de esta investigación fue evaluar cómo las CE actúan como estrategias de participación en el desarrollo del SUS. Se trata de una revisión integradora, con datos obtenidos de la búsqueda bibliográfica mediante los descriptores: participación popular, sistema único de salud y consejo de salud, se encontraron 66 artículos. Después de aplicar los criterios de elegibilidad y exclusión, se seleccionaron 22 artículos para el análisis, 9 indexados en la base de datos BVS y 13 en SciELO. Se encontró que las CS son herramientas estratégicas esenciales, presentándose como un canal directo entre la población y el desarrollo del SUS, sin embargo, aunque en algunos municipios su trabajo se está desarrollando en su totalidad, algunos municipios no cubren todas las atribuciones que son el derecho de la población. Las dificultades encontradas por los ayuntamientos involucran una serie de causas, que van desde el simple desinterés por los temas relacionados, hasta temas más complejos, como la falta de comunicación entre la administración y la comunidad, infraestructura inadecuada y falta de recursos financieros. Así, se necesitan estudios que discutan la participación de la CS como estrategias de participación popular en el SUS para construir nuevas estrategias que hagan más efectiva, activa y posible la planificación y participación en todo el país.

Palabras clave: Participación popular; Sistema único de salud; Consejos de salud.

\section{Introdução}

A criação do Sistema Único de Saúde (SUS), por meio do art. 196 da Constituição Federal de 1988 (Constituição, 1988), instituiu uma nova política de saúde, certificando-a como direito de todos e dever do Estado (Ventura et al., 2017), e o fortalecimento desse processo se deu mediante movimentos populares contra hegemônicos, descritos como processos emancipatórios, os quais propeliram a criação deste sistema (Busana et al., 2015; Oliveira \& Lima, 2016). Assim, a promulgação da Carta Magna promoveu a garantia da sociedade ao direito de participação e intervenção nas gestões da saúde.

A partir das leis 8.080 (1990) e 8.142 (1990) foram instituídos os Conselhos de Saúde (CS) nas três esferas governamentais, permitindo que a população incorpore e participe dos processos de criação, fiscalização, efetivação e manutenção de políticas voltadas para o atendimento necessário a cada localidade. É por meio destes conselhos que a sociedade, de modo democrático, atua no desenvolvimento do SUS (Pina, 2016). 
No contexto sociopolítico brasileiro, a partir da fundação do SUS, a saúde passa a revelar-se como uma questão ligada à cidadania, de forma que a atuação participativa política na gestão do sistema se transforma numa condição sine qua non para sua efetivação. Com isso, os CS se apresentam como elementos essenciais na participação da população nos processos de tomada de decisão, além de ser um método tático para a garantia da democratização do poder de decisões, em conjunto com a universalidade e equidade no SUS (Cotta et al., 2011).

A participação popular é definida por ações praticadas pelos cidadãos para monitorar, influenciar, executar, fiscalizar as políticas públicas por meio de gestão participativa efetivando a promoção da saúde (Busana et al., 2015). Assim, é considerando essa dinâmica, que a função atribuída ao CS e, por conseguinte, do controle social, se apresenta como uma das bases para a consolidação da Atenção Primária à Saúde. Esse conjunto de ideias se baseia na compreensão de que as pessoas que fazem uso dos serviços de saúde possuem maior legitimidade para realizar fiscalizações e acompanhamentos de tais serviços, podendo atuar de forma participativa nas deliberações sobre suas diretrizes (Busana et al., 2015).

A literatura que aborda a participação social em saúde no Brasil tem apontado dificuldades para a efetiva participação da sociedade civil nos CS, mostrando que esse funcionamento não acontece em todo o país de forma semelhante (Wendhausen \& Rodrigues, 2008; Morita et al., 2006; Silva, 2017).

Diante dessa realidade, torna-se oportuna, portanto, a avaliação do contexto de execução dos trabalhos dos CS na concepção de políticas públicas, visando à oportunidade de reconhecer as questões que existem nos espaços internos e externos dos conselhos, para com isso apontar intervenções com o objetivo de colaborar para o desenvolvimento da qualidade de vida e saúde da população. Dessa forma, objetivou-se com esta pesquisa avaliar como os CS atuam como estratégias de participação no desenvolvimento do SUS.

\section{Metodologia}

Trata-se de uma revisão integrativa, com finalidade analítica e objetivo qualitativo. Na área de saúde, as revisões assumem especial destaque entre os demais métodos para otimizar o conhecimento acerca da temática, nesse caso, o serviço de atenção à saúde mediante análise da gestão, o que justifica a observância precisa dos métodos de coleta de dados. Exatamente por isso a presente pesquisa buscou observar todos os rigores metodológicos científicos aplicáveis ao estudo da temática, desde a identificação do tema e estipulação de parâmetros de seleção do material de estudo, à literatura, passando pela delimitação dos dados a serem obtidos dos estudos e a respectiva análise minuciosa e seletiva, concluindo com a apreciação dos resultados e apresentação da conclusão.

O estudo se deu no segundo semestre de 2020, usando fontes secundárias, a partir das bases de dados da Biblioteca Virtual em Saúde (BVS), Literatura Internacional em Ciências da Saúde (PUBMED) e Scientific Electronic Library Online (SciELO), utilizando os descritores: 'participação popular', 'sistema único de saúde' e 'conselho de saúde', conforme estratégia de busca mediada pelo operador booleano "AND" (Figura 1). 
Figura 1 - Fluxograma das estratégias de busca dos artigos.

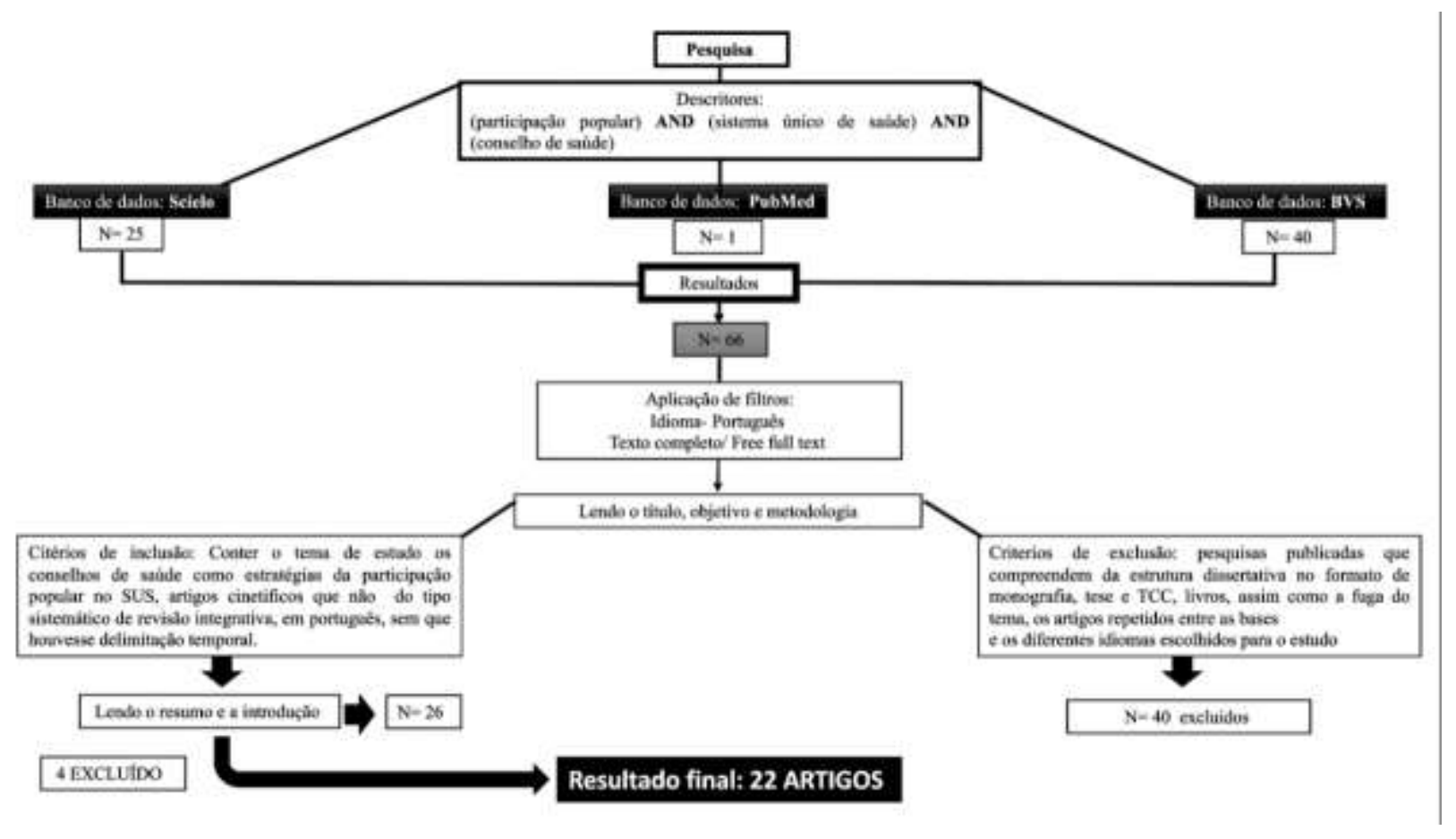

Fonte: Autores (2020).

Com o objetivo de filtrar as fontes selecionadas inicialmente, foram enumerados alguns critérios para inclusão: textos completos e na língua portuguesa, englobando a temática: participação popular na gestão do SUS, sem utilizar como critério de exclusão o período de publicação.

Em seguida, foi realizada a leitura criteriosa dos 66 artigos elegíveis - 40 artigos da BVS, 25 da SciELO, um da PUBMED - e foram estabelecidos os seguintes critérios de exclusão: duplicidade, texto em inglês, fuga do tema vigente no estudo, e tipos distintos de metodologia de estudo, tais como tese de doutorado, livro, monografia, trabalho de conclusão de curso (TCC), dissertação de mestrado. Resultaram 22 artigos para compor a amostra do estudo.

A organização dos dados encontrados se deu em quadro e fluxograma, a partir da utilização de softwares: Microsoft 365 Excel e Microsoft 365 Word. A análise dos dados foi estabelecida de forma qualitativa e quantitativa, segundo as variáveis: autor, revista, ano de publicação, base de dados, idioma e temática.

\section{Resultados e Discussão}

A partir da busca bibliográfica por meio dos descritores utilizados foram encontrados 66 artigos na busca inicial. Após serem aplicados os critérios de elegibilidade e exclusão, foram selecionados 22 artigos para análise, sendo nove indexados na base de dados BVS e 13 na SciELO. Na composição da amostra, a maioria dos artigos foram publicados no ano de 2017. A relação dos 22 artigos selecionados está apresentada no quadro 1 e a análise percentual do ano de publicação na Figura 2. 
Quadro 1 - Descrição dos autores, título, revista, objetivo, ano, base de dados e idioma dos artigos selecionados.

\begin{tabular}{|c|c|c|c|c|c|c|}
\hline AUTORES & TÍTULO & REVISTA & OBJETIVO & $\begin{array}{l}\text { BASE DE } \\
\text { DADOS }\end{array}$ & ANO & IDIOMA \\
\hline $\begin{array}{l}\text { Umberto Catarino Pessoto, } \\
\text { Paulo Roberto do } \\
\text { Nascimento e Luiza } \\
\text { Sterman Heimann }\end{array}$ & $\begin{array}{l}\text { A gestão semiplena e a } \\
\text { participação popular na } \\
\text { administração da saúde }\end{array}$ & $\begin{array}{l}\text { Cadernos de } \\
\text { Saúde Pública }\end{array}$ & $\begin{array}{l}\text { Verificar de que maneira essa norma influiu } \\
\text { no aprimoramento do conteúdo e das } \\
\text { formas de participação nas decisões das } \\
\text { políticas municipais de saúde. }\end{array}$ & SCIELO & 2001 & Português \\
\hline Valdir de Castro Oliveira & $\begin{array}{l}\text { Comunicação, informação e } \\
\text { participação popular nos } \\
\text { Conselhos de Saúde }\end{array}$ & $\begin{array}{l}\text { Saúde e } \\
\text { Sociedade }\end{array}$ & $\begin{array}{c}\text { Este trabalho discute a participação popular } \\
\text { nos conselhos de saúde e o papel da } \\
\text { comunicação e da informação nesse } \\
\text { processo. }\end{array}$ & SCIELO & 2004 & Português \\
\hline $\begin{array}{l}\text { Ione Morita, Julliano } \\
\text { Fernandes Campos } \\
\text { Guimarães e Bruno Paulino } \\
\text { Di Muzio }\end{array}$ & $\begin{array}{l}\text { A participação de } \\
\text { Conselheiros Municipais de } \\
\text { Saúde: solução que se } \\
\text { transformou em problema? }\end{array}$ & $\begin{array}{l}\text { Saúde e } \\
\text { Sociedade }\end{array}$ & $\begin{array}{l}\text { Analisar a participação dos segmentos que } \\
\text { compõem o Conselho Municipal de Saúde } \\
\text { de Botucatu, e, especificamente, a } \\
\text { representatividade dos conselheiros. }\end{array}$ & SCIELO & 2006 & Português \\
\hline Valdir de Castro Oliveira & $\begin{array}{l}\text { Desafios e contradições } \\
\text { comunicacionais nos } \\
\text { conselhos de saúde }\end{array}$ & $\begin{array}{l}\text { Mídia e saúde } \\
\text { pública }\end{array}$ & $\begin{array}{l}\text { Analisar os desafios e contradições } \\
\text { comunicacionais nos conselhos de saúde }\end{array}$ & BVS & 2006 & Português \\
\hline $\begin{array}{c}\text { Carlos Luiz da Silva } \\
\text { Pestana, Liliana Angel } \\
\text { Vargas e Fátima Teresinha } \\
\text { Scarparo Cunha }\end{array}$ & $\begin{array}{c}\text { Contradições surgidas no } \\
\text { Conselho Gestor da Unidade } \\
\text { Básica de Saúde da Família } \\
\text { de Vargem Grande, } \\
\text { Município de Teresópolis-RJ }\end{array}$ & $\begin{array}{l}\text { Physis: Revista } \\
\text { de Saúde } \\
\text { Coletiva }\end{array}$ & $\begin{array}{l}\text { Analisar a atuação desse Conselho na } \\
\text { resolução dos impasses e problemas } \\
\text { daquela comunidade e discutir as } \\
\text { contradições surgidas no processo de } \\
\text { tomada de decisões. }\end{array}$ & SCIELO & 2007 & Português \\
\hline $\begin{array}{l}\text { Águeda Lenita Pereira } \\
\text { Wendhausen e Ivia de } \\
\text { Fátima Rodrigues }\end{array}$ & $\begin{array}{l}\text { Concepções de saúde de } \\
\text { conselheiros municipais de } \\
\text { saúde da região da } \\
\text { AMFRI/SC e a relação com a } \\
\text { prática no conselho }\end{array}$ & $\begin{array}{l}\text { Ciência, Cuidado } \\
\text { e Saúde }\end{array}$ & Compreender Qs, & BVS & 2008 & Português \\
\hline $\begin{array}{l}\text { Poliana Cardoso Martins, } \\
\text { Rosangela Minardi Mitre } \\
\text { Cotta, Fábio Farias Mendes, } \\
\text { Sylvia do Carmo Castro } \\
\text { Franceschinni, Silvia Eloiza } \\
\text { Priore, Glauce Dias e } \\
\text { Rodrigo Siqueira-Batista }\end{array}$ & $\begin{array}{c}\text { Conselhos de saúde e } \\
\text { participação social no Brasil: } \\
\text { matizes da utopia }\end{array}$ & $\begin{array}{l}\text { Physis: Revista } \\
\text { de Saúde } \\
\text { Coletiva }\end{array}$ & $\begin{array}{l}\text { Analisar o processo de criação dos } \\
\text { conselhos de saúde no Brasil, descrevendo } \\
\text { sua importância para uma efetiva } \\
\text { participação da sociedade civil na tomada } \\
\text { de decisão na área da saúde, refletindo } \\
\text { sobre os matizes desta utopia. }\end{array}$ & BVS & 2008 & Português \\
\hline $\begin{array}{l}\text { José Patrício Bispo Júnior e } \\
\text { José Jackson Coelho } \\
\text { Sampaio }\end{array}$ & $\begin{array}{l}\text { Participação social em saúde } \\
\text { em áreas rurais do Nordeste } \\
\text { do Brasil }\end{array}$ & $\begin{array}{l}\text { Rev Panam Salud } \\
\text { Publica }\end{array}$ & $\begin{array}{c}\text { Analisar a participação social por meio dos } \\
\text { Conselhos Municipais de Saúde (CMS) em } \\
\text { dois municípios de pequeno porte do } \\
\text { Nordeste do Brasil. }\end{array}$ & SCIELO & 2008 & Português \\
\hline $\begin{array}{l}\text { Mauro Vieira e Maria } \\
\text { Cristina Marino Calvo }\end{array}$ & $\begin{array}{c}\text { Avaliação das condições de } \\
\text { atuação de Conselhos } \\
\text { Municipais de Saúde no } \\
\text { Estado de Santa Catarina, } \\
\text { Brasil }\end{array}$ & $\begin{array}{l}\text { Cadernos de } \\
\text { Saúde Pública }\end{array}$ & $\begin{array}{l}\text { Apresentar um modelo de avaliação da } \\
\text { participação da comunidade nos sistemas } \\
\text { de saúde municipais (condados). }\end{array}$ & SCIELO & 2011 & Português \\
\hline $\begin{array}{l}\text { Rosângela Minardi Mitre } \\
\text { Cotta, Poliana Cardoso } \\
\text { Martins, Rodrigo Siqueira } \\
\text { Batista, Sylvia do Carmo } \\
\text { Castro Franceschinni, Silvia } \\
\text { E. Priore e Fabio Faria } \\
\text { Mendes }\end{array}$ & $\begin{array}{l}\text { O controle social em cena: } \\
\text { refletindo sobre a } \\
\text { participação popular no } \\
\text { contexto dos Conselhos de } \\
\text { Saúde }\end{array}$ & $\begin{array}{l}\text { Physis: Revista } \\
\text { de Saúde } \\
\text { Coletiva }\end{array}$ & $\begin{array}{l}\text { Analisar a experiência do controle social, } \\
\text { via Conselho de Saúde - CS, em um } \\
\text { município de pequeno porte, utilizando o } \\
\text { referencial teórico da pesquisa qualitativa. }\end{array}$ & SCIELO & 2011 & Português \\
\hline $\begin{array}{l}\text { Amanda de Lucas Xavier } \\
\text { Martins e Sueli Maria dos } \\
\text { Reis Santos }\end{array}$ & $\begin{array}{l}\text { O exercício do controle social } \\
\text { no Sistema Único de Saúde: a } \\
\text { ótica do enfermeiro como } \\
\text { membro do conselho local de } \\
\text { saúde }\end{array}$ & $\begin{array}{l}\text { Saúde e } \\
\text { Sociedade }\end{array}$ & $\begin{array}{l}\text { Conhecer o posicionamento do enfermeiro } \\
\text { sobre sua atuação no Conselho Local de } \\
\text { Saúde frente ao princípio organizacional do } \\
\text { SUS de controle social no planejamento, } \\
\text { acompanhamento e avaliação das ações de } \\
\text { saúde }\end{array}$ & SCIELO & 2012 & Português \\
\hline $\begin{array}{c}\text { Claudia Jurberg, Eloy } \\
\text { Macchiute de Oliveira e } \\
\text { Eloiza da Silva Gomes de } \\
\text { Oliveira }\end{array}$ & $\begin{array}{c}\text { Capacitação para quê? O que } \\
\text { pensam conselheiros de saúde } \\
\text { da região Sudeste }\end{array}$ & $\begin{array}{l}\text { Ciência \& Saúde } \\
\text { Coletiva }\end{array}$ & $\begin{array}{l}\text { Averiguar a pertinência da construção de } \\
\text { uma comunidade de prática para } \\
\text { conselheiros de saúde dentro da política do } \\
\text { Sistema Único (SUS) de valorizar a } \\
\text { participação popular. }\end{array}$ & SCIELO & 2014 & Português \\
\hline
\end{tabular}




\begin{tabular}{|c|c|c|c|c|c|c|}
\hline $\begin{array}{l}\text { Milton Cordeiro Farias } \\
\text { Filho, Andréia Neves da } \\
\text { Silva e Armin Mathis }\end{array}$ & $\begin{array}{c}\text { Os limites da ação coletiva } \\
\text { nos Conselhos Municipais de } \\
\text { Saúde }\end{array}$ & $\begin{array}{c}\text { Ciência \& Saúde } \\
\text { Coletiva }\end{array}$ & $\begin{array}{c}\text { Verificar a atuação dos conselheiros nos } \\
\text { conselhos municipais de saúde da Região } \\
\text { Metropolitana de Belém (PA) }\end{array}$ & BVS & 2014 & Português \\
\hline $\begin{array}{l}\text { Juliano de Amorim Busana, } \\
\text { Ivonete Teresinha Schulter } \\
\text { Buss Heidemann e Águeda } \\
\text { Lenita Pereira Wendhausen }\end{array}$ & $\begin{array}{l}\text { Participação popular em } \\
\text { conselho local de saúde: } \\
\text { limites e potencialidades }\end{array}$ & $\begin{array}{c}\text { Texto \& } \\
\text { Contexto - } \\
\text { Enfermagem }\end{array}$ & $\begin{array}{c}\text { Analisar as potencialidades e limites da } \\
\text { participação popular nos conselhos locais } \\
\text { de saúde a partir do itinerário de pesquisa } \\
\text { de Paulo Freire. }\end{array}$ & SCIELO & 2015 & $\begin{array}{c}\text { Português } \\
\text { e Inglês }\end{array}$ \\
\hline $\begin{array}{c}\text { Andrecinda Rocha de } \\
\text { Morais Pina }\end{array}$ & $\begin{array}{c}\text { Participação popular em } \\
\text { saúde: um estudo sobre o } \\
\text { conselho regional de saúde de } \\
\text { Ceilândia, Distrito Federal- } \\
\text { Brasil }\end{array}$ & $\begin{array}{l}\text { Cad. Ibero-Amer. } \\
\text { Dir. Sanit. }\end{array}$ & $\begin{array}{c}\text { Entender como se dá a participação social } \\
\text { no Conselho Regional de Saúde de } \\
\text { Ceilândia na gestão. }\end{array}$ & BVS & 2016 & Português \\
\hline $\begin{array}{l}\text { Homero Nepomuceno } \\
\text { Duarte, Cristina M. } \\
\text { Athayde, José C. Ferreira, } \\
\text { Karina A. Viana, Lucio E. } \\
\text { Pereira, Shirlei Ap. de Sena } \\
\text { e Silvana Silva }\end{array}$ & Jornada Participativa do SUS & $\begin{array}{l}\text { VI Prêmio David } \\
\text { Capistrano de } \\
\text { Experiências } \\
\text { Exitosas dos } \\
\text { Municípios } \\
\text { Paulistas }\end{array}$ & $\begin{array}{c}\text { Avaliação minuciosa das eleições de } 2013 \text {, } \\
\text { identificando as dificuldades e falhas do } \\
\text { seu percurso. }\end{array}$ & BVS & 2016 & Português \\
\hline $\begin{array}{l}\text { Arena Carla Aparecida } \\
\text { Ventura, Marcela Jussara } \\
\text { Miwa, Mauro Serapioni e } \\
\text { Márjore Serena Jorge . }\end{array}$ & $\begin{array}{l}\text { Cultura participativa: } \\
\text { processo de construção da } \\
\text { cidadania no Brasil. }\end{array}$ & $\begin{array}{c}\text { Interface - } \\
\text { Comunicação, } \\
\text { Saúde, Educação }\end{array}$ & $\begin{array}{c}\text { Descrever os elementos - contexto e } \\
\text { recursos - que influenciam a participação } \\
\text { social em um Conselho Municipal de } \\
\text { Saúde (CMS) }\end{array}$ & SCIELO & 2017 & $\begin{array}{c}\text { Português } \\
\text { e Inglês }\end{array}$ \\
\hline $\begin{array}{l}\text { Rosalvo de Jesus Oliveira e } \\
\text { Wilza Carla Mota Brito } \\
\text { Lima. }\end{array}$ & $\begin{array}{c}\text { Participação social no } \\
\text { Sistema Único de Saúde: o } \\
\text { envolvimento da população } \\
\text { de Alagoinhas }\end{array}$ & $\begin{array}{l}\text { Rev. baiana } \\
\text { saúde pública }\end{array}$ & $\begin{array}{c}\text { Analisar a participação da população de } \\
\text { Alagoinhas, Bahia, no Sistema Único de } \\
\text { Saúde. }\end{array}$ & BVS & 2017 & Português \\
\hline Rosimary Bernardes Silva & $\begin{array}{c}\text { Atuação e competência do } \\
\text { Conselho Municipal de Saúde } \\
\text { Santo Antônio do Descoberto, } \\
\text { DF }\end{array}$ & $\begin{array}{l}\text { Cad. Ibero-Amer. } \\
\text { Dir. Sanit. }\end{array}$ & $\begin{array}{c}\text { Analisar a Atuação e competência do } \\
\text { Conselho Municipal de Saúde Santo } \\
\text { Antônio do Descoberto, DF }\end{array}$ & BVS & 2017 & Português \\
\hline $\begin{array}{c}\text { Pamela Cristina Bianchia e } \\
\text { Stella Maris Nicolaub }\end{array}$ & $\begin{array}{l}\text { Trajetórias de conselheiros de } \\
\text { saúde: refletindo sobre } \\
\text { cultura política e participação } \\
\text { popular }\end{array}$ & $\begin{array}{l}\text { Cadernos } \\
\text { Brasileiros de } \\
\text { Terapia } \\
\text { Ocupacional }\end{array}$ & $\begin{array}{l}\text { Compreender as trajetórias de conselheiros } \\
\text { municipais de saúde representantes dos } \\
\text { usuários e traçar reflexões a respeito da } \\
\text { participação popular e da cultura política na } \\
\text { realidade de um município de médio porte } \\
\text { do interior paulista. }\end{array}$ & BVS & 2017 & Português \\
\hline $\begin{array}{l}\text { Jéssica Ferreira, Ianka } \\
\text { Cristina Celuppi, Lilian } \\
\text { Baseggio, Daniela Savi } \\
\text { Geremia, Valéria Silvana } \\
\text { Faganello, Madureira e } \\
\text { Jeane Barros de Souza }\end{array}$ & $\begin{array}{l}\text { Planejamento regional dos } \\
\text { serviços de saúde: o que } \\
\text { dizem os gestores? }\end{array}$ & $\begin{array}{l}\text { Saúde e } \\
\text { Sociedade }\end{array}$ & $\begin{array}{l}\text { Analisar a percepção dos gestores de saúde } \\
\text { sobre o planejamento regional dos } \\
\text { municípios do oeste catarinense, tendo em } \\
\text { vista os principais fatores que influenciam } \\
\text { na gestão pública para a organização da } \\
\text { rede de serviços de saúde }\end{array}$ & SCIELO & 2018 & Português \\
\hline $\begin{array}{l}\text { Ilma de Paiva Pereira, } \\
\text { Cássius Guimarães Chai, } \\
\text { Rosane da Silva Dias, } \\
\text { Cristina Maria Douat } \\
\text { Loyola e Marcos Antônio } \\
\text { Barbosa Pacheco }\end{array}$ & $\begin{array}{c}\text { Ministério Público, } \\
\text { Conselhos Municipais de } \\
\text { Saúde e as práticas do diálogo } \\
\text { interinstitucional }\end{array}$ & $\begin{array}{l}\text { Saúde e } \\
\text { Sociedade }\end{array}$ & $\begin{array}{l}\text { Analisar o relacionamento entre o } \\
\text { Ministério Público e os Conselhos } \\
\text { Municipais de Saúde (CMS), buscando } \\
\text { refletir de que maneira aquela instituição } \\
\text { pode contribuir para a efetividade do } \\
\text { controle social exercido no Sistema Único } \\
\text { de Saúde (SUS) no estado do Maranhão. }\end{array}$ & SCIELO & 2019 & $\begin{array}{c}\text { Português } \\
\text { e Inglês }\end{array}$ \\
\hline
\end{tabular}

Fonte: Autores. 
Figura 2 - Distribuição gráfica da amostra do estudo descritivo do material considerando o ano de publicação.

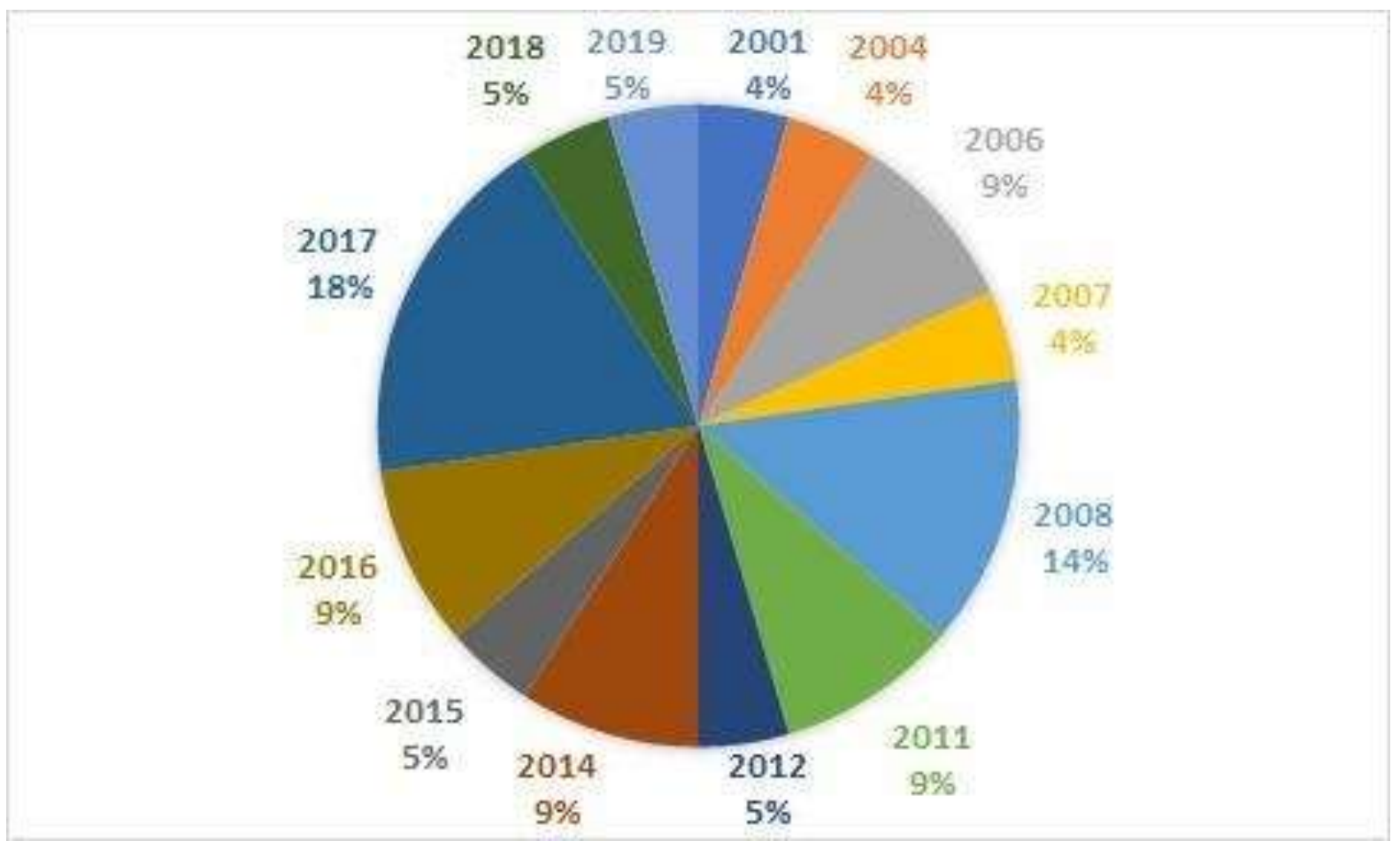

Fonte: Autores (2020).

O SUS surgiu para legitimar os artigos da Constituição Federal de 1988 (Constituição, 1988) que abordam a saúde no Brasil. Seguindo a Constituição Federal, foram consentidos alguns pontos cruciais para o âmbito da saúde no país, tais quais estão a: universalização da concessão à saúde, a saúde como responsabilidade do Estado e a construção do SUS para possibilitar a agregação de todas as atividades de saúde em uma só rede, assegurando, assim, de modo legal, o amparo à saúde da população brasileira (Ventura et al., 2017).

Entretanto, nem sempre foi assim. O âmbito da saúde enfrentou transformações sob a intervenção dos contextos social e político que o Brasil manteve ao longo dos anos. Nessa jornada, foram poucos os investimentos governamentais voltados à saúde pública. Por meio das movimentações trabalhistas, que resultaram em duas grandes greves, ocorridas nos anos de 1917 e 1919, a classe operária começou a adquirir alguns direitos sociais, como a normalização das Caixas de Aposentadoria e Pensão (CAP), a normalização da justiça do trabalho em 1939, a aprovação da Consolidação das Leis Trabalhistas (CLT), em 1943, o Serviço de Assistência Médica Domiciliar e de Urgência (SAMDU) e a origem do Ministério da Saúde (MS), em 1953 (Oliveira \& Lima, 2016).

Os CS aparecem, então, como desdobramentos da movimentação da saúde popular, consistindo em fóruns públicos para, entre outras coisas, reivindicação de melhoramento no sistema de saúde. Tal movimentação teve forte influência na apresentação do SUS e papel significativo na redemocratização do país (Oliveira, 2004; Pina, 2016).

Portanto, estes tornam-se setores para a inter-relação das políticas no âmbito da saúde, nas atuações do Estado e no exercício da condição de cidadão, com o intuito de potencializar o comando social no gerenciamento do SUS. Dessa maneira, tal conjuntura vem se consolidando por meio de leis, portarias e recomendações pelo governo federal, que apontam para a relevância dos CS como ambientes para a execução do controle social e a consolidação da cidadania (Busana et al., 2015).

É por meio da atuação popular nos CS, associada à vontade de desempenhar transformações sociais e políticas, que este método se constitui como instrumento fundamental para o desenvolvimento do empoderamento pessoal e comunitário, em 
virtude de que tal procedimento altera o status quo ao proporcionar uma consciência política e desencadear autonomia para a tomada de escolha (Busana et al., 2015; Jurbeger et al., 2014).

A participação cidadã na área da saúde se mostra de diversas formas: como beneficiário, além de contribuinte para a promoção da saúde, participando por meio do apoio voluntário aos programas e projetos de desenvolvimento social; assim como participação comunitária, organizando grupos de apoio aos programas e projetos; e, finalmente, a participação em saúde que garante as pessoas como usuárias e cidadãs, sendo, portanto, credoras de prestação de contas quanto ao seu funcionamento, permitindo maior controle sobre seus direitos a uma boa proteção à saúde (Martins et al., 2008).

Contudo, no Brasil, ainda que haja esforços para fortalecer esse olhar mais moderno e complexo de atuação, enfatizase a complicação da população em se identificar como parte da estruturação das políticas de saúde, questão que por vezes é prejudicada pela maneira como foram desigualmente constituídos os serviços de saúde ao decorrer da história, enfraquecendo a promoção da autonomia, de forma que mecanismos de movimentação de recursos particulares e comunitários devem incentivar a autonomia dos cidadãos e comunidades com o propósito de fortificar elementos protetores e promotores de saúde (Wendhausen \& Rodrigues, 2008; Morita et al., 2006; Silva, 2017).

Pesquisas apontam que o desempenho dos CS é desigual por todo o país, por consequência de que muitas regiões exibem inúmeros entraves para seu exercício (Martins et al., 2008), como a incompreensão das atribuições dos papéis, desarticulação entre as classes, a complexidade de utilizar o computador e internet, ausência de resolutividade das práticas e níveis primários de envolvimento social, uma vez que muitas exigências não tiveram a atenção crucial por parte dos gestores e do comitê municipal, ocasionando declinação e desinteresse dos cidadãos nesse ambiente de participação (Pestana et al., 2007; Pereira et al., 2019).

Ventura et al. (2017) relatam como entraves dessa participação a carência de quórum deliberativo, cidadãos se expressando de forma particular e não estruturada comunitariamente, objeções físicas e organizacionais para a atuação, infraestrutura inapropriada, carência de recursos financeiros, e lacunas na qualificação dos conselheiros, com isso, a falta de movimentos educacionais é um agravante, tendo em vista que a atuação dos usuários no conselho é de grande importância para a completude da atuação na saúde pelos gestores.

Já o estudo de Vieira e Calvo (2011) elaborou um sistema de análise das situações de desempenho dos CS, através da sua aplicabilidade em 24 municípios de duas associações de municípios de Santa Catarina. Os resultados comprovaram a possibilidade da aplicação da maior parte dos critérios propostos, a exceção de dois critérios da dimensão sistémica de planejamento do SUS e de dois critérios da dimensão organizacional dinâmica que se apresentaram pouco discriminatórios, corroborando com Ventura et al. (2017), que também encontraram entraves no planejamento e organização.

De modo semelhante, na pesquisa de Cotta et al. (2011), ao analisarem a experiência do domínio social, mediante CS, em um município de pequeno porte, observaram que a perspectiva de uma gestão participativa no SUS não se estabeleceu como uma prática satisfatória; o que se constatou foi um enorme desconhecimento sobre as parâmetros legais e ideológicos da participação comunitária em saúde, possibilitando assim uma forte influência dos gestores regionais na dinâmica e no desempenho do CS, em especial na indicação de seus integrantes, dificultando, desse modo, que esse seja um ambiente concreto para que os cidadãos se adaptem de modo institucional e político do conselho.

Os resultados de Cotta et al. (2011) corroboram com os encontrados por Farias Filho, Silva e Mathis (2014), em uma abordagem sobre as ações coletivas de participação nos CS da Região Metropolitana de Belém (PA); os resultados dos autores apontaram que as condutas dos conselhos são delimitadas por cooptação de conselheiros, estabelecimento de agendas decretadas por parte de representantes da direção, prevalecendo os interesses particulares dos conselheiros sobre os interesses comunitários nas deliberações, onde tais procederes entram em contradição com os princípios do SUS e enfraquecem a figura social dos conselhos. 
Ainda, de modo semelhante, Ferreira et al. (2018), ao analisarem o discernimento dos gestores de saúde sobre a organização regional dos municípios do oeste catarinense, constataram, a partir das entrevistas com os gestores, que entre os eminentes obstáculos para concretização da organização, estão a falta de compreensão das atribuições do gestor; a exorbitância de trabalho enfrentada pelo grupo auxiliário, que atrapalha a organização compartilhada; e os problemas de pactuação/regionalização entre as cidades do oeste catarinense em razão das situações sociais, econômicas e de propostas de serviços de saúde.

Nesse sentido, é necessário observar as estratégias de participação social no Brasil através da participação social e amadurecimento da política social (Bispo Júnior \& Sampaio, 2008). Em seu estudo, que objetivou analisar a participação social por meio dos CS em dois municípios de pequeno porte do Nordeste do Brasil, Bispo Júnior e Sampaio (2008) observaram irregularidades da composição e posse dos conselheiros, pois apresentaram alta rotatividade de representantes e renovação integral do quadro quando da posse de um novo prefeito, além de irregularidades na frequência de reunião, que não atingia o número previsto. Os resultados dos autores ainda mostraram insatisfação e descrença por parte os participantes em relação as práticas e ao poder desses conselhos.

Outro ponto importante observado na literatura se refere à participação do enfermeiro nos CS. Nesse sentido, a pesquisa de Martins e Santos (2012) que analisou o posicionamento desse profissional a respeito da sua conduta no CS diante o conceito organizacional do SUS, foi denotada então a importância desse exercício na gestão em razão da sua formação direcionada para a prática de saúde pública e social. Entretanto, vários entrevistados ainda presumem que o emprego do Enfermeiro no CS é relevante somente como possibilidade para transmitir atuações e necessidades do serviço de atenção básica à saúde.

De acordo Bianchi e Nicolau (2017), embora os problemas encontrados no ofício da colaboração popular no município, nota-se que vem sendo traçado um estágio de transição da cultura política regional com a efetivação e a implementação do CS. Parte-se da concepção tradicional e autoritária, nas deliberações políticas, para a eficácia do controle social e o empoderamento dos usuários, em uma geração política participativa e democrática.

Assim, entendemos que o âmbito dos conselhos é um setor de aprendizagem cidadã, e que a formação ou qualificação dos conselheiros (usuários, trabalhadores e gestor) não pode ser limitada apenas ao papel instrumental diante à verticalidade da jurisdição, mas sim de maneira que todos possam, mutuamente, se transfigurar dialogicamente com o propósito de democratizar e aprimorar a saúde pública. Afinal nenhuma pessoa nasce cidadão ou conselheiro. Tanto uma coisa quanto outra necessita de investimentos e de instrução, como faziam alguns gregos que capacitavam e predeterminavam os indivíduos para operar na Ágora, onde aconteciam os debates públicos, isto é, preparando-os por meio da retórica para resguardar os seus pontos de vista em equidade de condições com os outros, já que a concepção entre eles era a de que não poderia haver democracia com indivíduos em circunstâncias desiguais (Oliveira, 2006; Pessoto et al., 2001; Duarte et al., 2016).

\section{Considerações Finais}

A partir da metodologia adotada e dos resultados obtidos, constatou-se que os CS são ferramentas de estratégia essenciais para a formulação, execução, fiscalização e avaliação de políticas públicas voltadas para os serviços de saúde, se apresentando como um canal direto entre a população e o desenvolvimento do SUS.

Os resultados ainda demonstraram que, embora em alguns municípios a atuação dos CS esteja sendo desenvolvida em sua totalidade, a maioria não abarca todas as atribuições que são direito da população, tornando essa prática insatisfatória diante das necessidades da sociedade civil. As dificuldades encontradas pelos CS envolvem uma série de causas, que vão desde o simples desinteresse pelas questões relativas ao conselho, ao SUS e aos parâmetros legais e ideológicos da participação comunitária em saúde, até questões mais complexas, como falta de comunicação, infraestrutura indevida, falta de recurso financeiro, condutas de interesse particular e nomeação de membros sem o cumprimento das formais normais de aceitação. 
Com isso, fica clara a necessidade em desenvolver estratégias que promovam a participação, e consequente qualificação de conselheiros para atuar no desenvolvimento do SUS, de forma a garantir a qualidade de vida e saúde da população. Por fim, mais estudos que discutam a participação dos CS como estratégias para participação popular no SUS são necessários para a construção de novas estratégias que possam tornar o planejamento e participação mais efetivas, atuantes e possíveis de serem realizadas em todo o país.

\section{Referências}

Bianchi, P. C., \& Nicolau, S. M. (2017). Trajetórias de conselheiros de saúde: refletindo sobre cultura política e participação popular/Trajectories of health counselors: reflecting on political culture and popular participation. Cadernos Brasileiros de Terapia Ocupacional, 25(1). www.cadernosdeterapiaocupacional.ufscar.br/index.php/cadernos/article/view/1330/814

Bispo Júnior, J. P., \& Sampaio, J. J. C. (2008). Participação social em saúde em áreas rurais do Nordeste do Brasil. Revista Panamericana de Salud Pública, 23, 403-409. https://www.scielosp.org/pdf/rpsp/2008.v23n6/403-409/pt

Busana, J. D. A., Heidemann, I. T. S. B., \& Wendhausen, Á. L. P. (2015). Participação popular em um conselho local de saúde: limites e potencialidades. Texto \& Contexto-Enfermagem, 24, 442-449. https://www.scielo.br/scielo.php?pid=S0104-07072015000200442\&script=sci_arttext\&tlng=pt

Constituição da $\quad$ República $\quad$ Federativa $\quad$ do $\quad$ Brasil $\quad$ de $\quad$ Brasília. https://www2.senado.leg.br/bdsf/bitstream/handle/id/518231/CF88_Livro_EC91_2016.pdf Constituiçao.htm

Cotta, R. M. M., Martins, P. C., Batista, R. S., Franceschinni, S. D. C. C., Priore, S. E., \& Mendes, F. F. (2011). O controle social em cena: refletindo sobre a participação popular no contexto dos Conselhos de Saúde. Physis: revista de saúde coletiva, 21 , 1121-1138. https://www.scielosp.org/pdf/physis/2011.v21n3/1121-1138/pt

Duarte, H. N., Athayde, C. M., Ferreira, J. C., Viana, K. A., Pereira, L. E., Sena, S. A., \& Silva, S. (2016). Jornada Participativa do SUS. BIS, Bol. Inst. Saúde (Impr.), 22-26. docs.bvsalud.org/biblioref/2019/10/1022878/bis-v17-suplemento-2016-22-26.pdf

Farias Filho, M. C., Silva, A. N. D., \& Mathis, A. (2014). Os limites da ação coletiva nos Conselhos Municipais de Saúde. Ciência \& Saúde Coletiva, 19, 19111919. https://www.scielosp.org/pdf/csc/2014.v19n6/1911-1919/pt

Ferreira, J., Celuppi, I. C., Baseggio, L., Geremia, D. S., Madureira, V. S. F., \& Souza, J. B. D. (2018). Planejamento regional dos serviços de saúde: o que dizem os gestores?. Saúde e Sociedade, 27, 69-79. https://www.scielosp.org/article/sausoc/2018.v27n1/69-79/pt/

Jurberg, C., Oliveira, E. M. D., \& Oliveira, E. D. S. G. D. (2014). Capacitação para quê? O que pensam conselheiros de saúde da região Sudeste. Ciência \& Saúde Coletiva, 19, 4513-4523. scielosp.org/article/csc/2014.v19n11/4513-4523/

Lei no 8.080, de 19 de setembro de 1990. (1990). Dispõe sobre as condições para a promoção, proteção e recuperação da saúde, a organização e o funcionamento dos serviços correspondentes e dá outras providências. Brasília. www.planalto.gov.br/ccivil_03/leis/18080.htm

Lei $\mathrm{n}^{\circ}$ 8.142, de 28 de dezembro de 1990. (1990). Dispõe sobre a participação da comunidade na gestão do Sistema Único de Saúde (SUS) e sobre as transferências intergovernamentais de recursos financeiros na área da saúde e dá outras providências. Congresso Nacional. www.planalto.gov.br/ccivil_03/leis/18142.htm

Martins, A. D. L. X., \& Santos, S. M. D. R. (2012). O exercício do controle social no Sistema Único de Saúde: a ótica do enfermeiro como membro do conselho local de saúde. Saúde e Sociedade, 21, 199-209. https://www.scielosp.org/pdf/sausoc/2012.v21suppl1/199-209/pt

Martins, P. C., Cotta, R. M. M., Mendes, F. F., Franceschinni, S. D. C. C., Priore, S. E., Dias, G., \& Siqueira-Batista, R. (2008). Conselhos de saúde e a participação social no Brasil: matizes da utopia. Physis: Revista de Saúde Coletiva, 18, 105-121. https://www.scielosp.org/pdf/physis/2008.v18n1/105-121/pt

Morita, I., Guimarães, J. F. C., \& Di Muzio, B. P. (2006). A participação de Conselheiros Municipais de Saúde: solução que se transformou em problema?. Saúde e sociedade, 15, 49-57. https://www.scielo.br/scielo.php?pid=S0104-12902006000100006\&script=sci_arttext\&tlng=pt

Oliveira, R. J., \& Lima, W. C. M. B. (2016). Participação social no Sistema Único de Saúde: o envolvimento da população de Alagoinhas. Revista Baiana de Saúde Pública, 40(4). https://pesquisa.bvsalud.org/portal/resource/pt/biblio-876092?lang=pt

Oliveira, V. C. (2006). Desafios e contradições comunicacionais nos conselhos de saúde. Caderno mídia e saúde pública, 83. iah.iec.pa.gov.br/iah/fulltext/pc/monografias/outros/midiasaude.pdf\#page=83

Oliveira, V. D. C. (2004). Comunicação, informação e participação popular nos conselhos de saúde. Saúde e sociedade, 13, 56-69. https://www.scielosp.org/pdf/sausoc/2004.v13n2/56-69/pt

Pereira, I. D. P., Chai, C. G., Dias, R. D. S., Loyola, C. M. D., \& Pacheco, M. A. B. (2019). Ministério Público, Conselhos Municipais de Saúde e as práticas do diálogo interinstitucional. Saúde e Sociedade, 28, 111-123. https://www.scielosp.org/pdf/sausoc/2019.v28n2/111-123/pt

Pessoto, U. C., Nascimento, P. R. D., \& Heimann, L. S. (2001). A gestão semiplena e a participação popular na administração da saúde. Cadernos de Saúde Pública, 17, 89-97. https://www.scielosp.org/article/csp/2001.v17n1/89-97/

Pestana, C. L. D. S., Vargas, L. A., \& Cunha, F. T. S. (2007). Contradições surgidas no conselho gestor da unidade básica de saúde da família de Vargem Grande, Município de Teresópolis-RJ. Physis: Revista de Saúde Coletiva, 17, 485-499. https://www.scielosp.org/article/physis/2007.v17n3/485-499/ 
Research, Society and Development, v. 10, n. 17, e17101724186, 2021

(CC BY 4.0) | ISSN 2525-3409 | DOI: http://dx.doi.org/10.33448/rsd-v10i17.24186

Pina, A. R. M. (2016). Participação popular em saúde: um estudo sobre o conselho regional de saúde de Ceilândia, Distrito Federal-Brasil. Cadernos IberoAmericanos de Direito Sanitário, 5(1), 234-254. https://www.cadernos.prodisa.fiocruz.br/index.php/cadernos/article/view/283

Silva, R. B. (2017). Atuação e competência do Conselho Municipal de Saúde Santo Antônio do Descoberto, DF. Cadernos Ibero-Americanos de Direito Sanitário, 6(3), 90-100. https://www.cadernos.prodisa.fiocruz.br/index.php/cadernos/article/view/380

Ventura, C. A. A., Miwa, M. J., Serapioni, M., \& Jorge, M. S. (2017). Cultura participativa: um processo de construção de cidadania no Brasil. InterfaceComunicação, Saúde, Educação, 21, 907-920. https://www.scielosp.org/article/icse/2017.nahead/10.1590/1807-57622015.0941/

Vieira, M., \& Calvo, M. C. M. (2011). Avaliação das condições de atuação de Conselhos Municipais de Saúde no Estado de Santa Catarina, Brasil. Cadernos de Saúde Pública, 27(12), 2315-2326. https://www.scielo.br/pdf/csp/v27n12/04.pdf

Wendhausen, Á. L. P., \& Rodrigues, I. F. (2006). Concepções de saúde de conselheiros municipais de saúde da região da AMFRI/SC e a relação com a prática no conselho. Ciência, Cuidado e Saúde, 5(2), 166-174. periodicos.uem.br/ojs/index.php/CiencCuidSaude/article/view/5072 